\title{
Characterization of the Resin Luting Materials: Percentage, Morphology and Mechanical Properties
}

\author{
Sarr $\mathrm{M}^{* 1}$, Leye-Benoist $\mathrm{F}^{1}$, Aidara $\mathrm{AW}^{2}$, Faye $\mathrm{B}^{1}$, Bane $\mathrm{K}^{2}$ and Touré $\mathrm{B}^{1}$ \\ ${ }^{1}$ Professor Department of Conservative Dentistry and Endodontics University Cheikh Anta Diop, Dakar-Liberté, \\ Sénégal \\ ${ }^{2}$ Assistant Professor Department of Conservative Dentistry and Endodontics University Cheikh Anta Diop, Dakar, \\ Sénégal
}

${ }^{*}$ Corresponding author: Sarr M, Professor, Department of Conservative Dentistry and Endodontics University Cheikh Anta Diop BP 17256, Dakar-Liberté, Sénégal, Tel: 00.221.77.632.06.78, E-mail: mouhamedsarr@ yahoo.com

Citation: Sarr M, Leye-Benoist F, Aidara AW, Faye B, Bane K, et al. (2016) Characterization of the Resin Luting Materials: Percentage, Morphology and Mechanical Properties. J Dent Oral Care Med 2(3): 303. doi: $10.15744 / 2454-3276.2 .303$

Received Date: August 04, 2016 Accepted Date: August 29, 2016 Published Date: August 30, 2016

\begin{abstract}
Aim: The purpose of this study was: 1) to determine the percentage of fillers by weight of the investigated materials by thermogravimetric analysis (TGA), to examine their fillers morphology using scanning electron microscopy (SEM), 2) and to evaluate the mechanical properties of these materials.

Methods: Seven luting materials (Rely X Unicem, Maxcem, Monocem, G-Cem, Panavia F2, Variolink II and Clearfil Esthetic Cement) and the micro-hybrid resin composite Clearfil AP-X (control) were evaluated. Thermogravimetric analysis (TGA) was used to determine the percentage of fillers by weigh and the fillers morphology was determined using scanning electron microscopty (SEM). Regarding mechanical properties, five specimens of each material were used to measure dynamic and static moduli of elasticity and Vickers microhardness.

Results: The percentage of fillers by weight ranged between 60\% (Monocem) and 73\% (Variolink II). For the micro-hybrid resin composite Clearfil AP-X used as control, the weight percentage of fillers was $83.5 \%$.

Some values in this study were different from those given by the manufacturers. SEM photographs showed various shapes and sizes of inorganic fillers. Irregular shaped particles were found in Maxcem, Monocem and Variolink II. Rely X Unicem showed large irregular shaped filler aggregates. Irregular and spheroidal particles associated with aggregates were found in Panavia F2, Clearfil Esthetic Cement, G-Cem and Clearfil AP-X.

Variations in mechanical properties were observed within the tested materials.

Conclusion: Wide variations in morphology and percentage of fillers were observed between our TGA's data and those given by the manufacturers and will probably affect the mechanical properties of luting materials.
\end{abstract}

Keywords: Characterization; Fillers; Luting cements; Morphology; Percentage

\section{Introduction}

As an esthetic alternative to amalgam for the restoration of posterior teeth, resin-composites are being increasingly employed. Limitations regarding these materials concern limited strength, toughness and durability, although more recent formulations have better survival [1]. Despite these improvements, the effects of polymerization shrinkage remain a cause for concern. Thus, the use of indirect ceramic or resin composite restorations has increased thanks to their higher aesthetic properties and wears resistance [2]. Such restorations need to be cemented adhesively and various commercial luting materials are available for that purpose.

The behaviour of these luting cements partially depends on percentages, composition, dimensions and shape of their fillers. Several authors have demonstrated that mechanical properties are better correlated to the filler fraction of the resin composite [3-6]. Other authors studied the effect of fillers size and shape on mechanical properties $[7,8]$.

The aim of this study was to characterize the inorganic fraction of luting materials regarding percentage and morphology of filler particles and to evaluate the mechanical properties of these materials. The null hypothesis is that there is no difference in fillers percentage between manufacturers and TGA's data among cements. 


\section{Materials and Methods}

Seven commercial are listed respectively: Rely X Unicem, Maxcem, Monocem, G-Cem, Panavia F2, Variolink II and Clearfil Esthetic Cement. As control, the micro-hybrid resin composite Clearfil AP-X (Kuraray) was used.

The composite cements tested in this study are described in Table 1.

\begin{tabular}{|c|c|}
\hline $\begin{array}{l}\text { Luting cements, } \\
\text { Manufacturer and } \\
\text { batch number }\end{array}$ & Composition \\
\hline $\begin{array}{l}\text { RELYX UNICEM } \\
\text { (Aplicap) } \\
\text { 3M Espe, Seefeld, } \\
\text { Germany } \\
\text { Lot } 256677\end{array}$ & $\begin{array}{l}\text { Powder: Glass fillers, silica, calcium hydroxide, self-curing initiators, } \\
\text { pigments, light-curing initiators } \\
\text { Liquid: methacrylated phosphoric esters, dimethacrylates, acetate, stabilizers, } \\
\text { self-curing and light -curing initiators }\end{array}$ \\
\hline $\begin{array}{l}\text { MAXCEM } \\
\text { Kerr, Orange, USA } \\
\text { Lot } 32857\end{array}$ & $\begin{array}{l}\text { Glycerol dimethacrylate dihydrogen phosphate (GPDM), co-monomers } \\
\text { (mono-, di- and tri functional methacrylate monomers), self-curing redox } \\
\text { activator, photoinitiator (camphorquinone), stabilizer, barium glass fillers, } \\
\text { fluoroaluminosilicate glass filler, fumed silica }\end{array}$ \\
\hline $\begin{array}{l}\text { MONOCEM } \\
\text { Shofu, Kyoto, Japan } \\
\text { Lot } 060605\end{array}$ & Mono-, di and multifunctional acrylate resins, dual-initiators and fillers. \\
\hline $\begin{array}{l}\text { G-CEM } \\
\text { GC, Japan } \\
\text { Lot } 0608220\end{array}$ & $\begin{array}{l}\text { Liquid: 4-MET, phosphoric acid ester monomer, water, UDMA, } \\
\text { dimethacrylate, silica powder, initiator, stabilizer } \\
\text { Powder: Fluoro-alumino-silicate glass, initiator, pigment }\end{array}$ \\
\hline $\begin{array}{l}\text { PANAVIA F2.0 } \\
\text { Kuraray, Japan } \\
\text { Lot } 41196\end{array}$ & $\begin{array}{l}\text { Base: hydrophobic aromatic and aliphatic dimethacrylate, } \\
\text { sodium aromatic sulphinate, } \mathrm{N}, \mathrm{N} \text {-diethanol-p-toluidine, sodium fluoride, } \\
\text { silanized barium glass } \\
\text { Catalyst: MDP, hydrophobic aromatic and aliphatic photoinitiator, dibenzoyl } \\
\text { peroxide dimethacrylate, hydrophilic dimethacrylate, silanized silica }\end{array}$ \\
\hline $\begin{array}{l}\text { Clearfil Esthetic } \\
\text { Cement } \\
\text { Kuraray, Tokyo, } \\
\text { Japan } \\
\text { Lot } 41111\end{array}$ & $\begin{array}{l}\text { Paste A: Bis-GMA, TEG-DMA, others methacrylate monomers, silanated } \\
\text { glass filler, colloidal silica } \\
\text { Paste B: Bis-GMA, TEG-DMA, others methacrylate monomers, silanated } \\
\text { glass filler, silanated silica, colloidal silica, benzoyle peroxide, di- } \\
\text { camphorquinone, pigments }\end{array}$ \\
\hline $\begin{array}{l}\text { VARIOLINK II } \\
\text { Ivoclar-Vivadent, } \\
\text { Schaan, } \\
\text { Liechtenstein } \\
\text { Lot J22596 }\end{array}$ & $\begin{array}{c}\text { BisGMA, UDMA, TEGDMA, barium glass fillers, ytterbium trifluoride, } \\
\text { boroaluminofluorosilicate glass, spheroidal mixed oxide, catalysts, stabilizers, } \\
\text { pigments }\end{array}$ \\
\hline $\begin{array}{l}\text { CLEARFIL AP-X } \\
\text { [Lot 000125] } \\
\text { (Shade A3) }\end{array}$ & \\
\hline
\end{tabular}

Abbreviations: Bis-GMA: bisphenol A glycidyl methacrylate; GPDM: Glycerol dimethacrylate dihydrogen phosphate; HEMA: Hydroxy ethyl methacrylate; 4-MET: 4-methacryloyloxyethyl trimellitic acid; 5-NMSA: N-methacryloyl 5-aminosalicylic acid; 10MDP: 10-methacryloyloxy decyl dihydrogenphosphate acid; PENTA: dipentaerythritol penta acrylate monophosphate; TEGDMA: triethylene glycol dimethacrylate; UDMA: urethane dimethacrylate.

Table 1: Composition of the composite cements tested (technical information provided by the respective manufacturers)

\section{Weight percentage of fillers}

Thermogravimetric analysis (TGA) was used to determine the percentage of fillers by weight using a thermogravimetric Analyser (Perkin-Elmer TGA-7, USA). Weight changes were evaluated as a function of time and temperature during a thermal program ranging from $30{ }^{\circ} \mathrm{C}$ to $900{ }^{\circ} \mathrm{C}$ at the rate of $10^{\circ} \mathrm{C} / \mathrm{min}$ in normal atmosphere followed by air cooling to room temperature. The calculated ratio between the final weight of the sample and its nominal weight is assigned to the inorganic fraction. Three samples of each material were analyzed.

\section{Fillers morphology}

The fillers morphology was determined using scanning-electron microscopy (SEM). Unpolymerized monomers were removed by a washing technique [9]. A sample of $0.5 \mathrm{~g}$ of each material was dissolved in $4 \mathrm{ml}$ of acetone and centrifuged for 5 seconds at 2000 $\mathrm{rpm}$. This process was repeated three times using acetone and three others with chloroform for a further washing and elimination of the unpolymerized resin. The remaining filler particles including the prepolymerized fillers were placed in $3 \mathrm{ml}$ of absolute ethanol and the suspension of filler particles was smeared on glass slide $(7.5 \times 2.5 \mathrm{~cm})$ and dried at $37^{\circ} \mathrm{C}$ during 6 hours. After gold-coating of the specimens (Leica EM ACE600, Germany), fillers were observed by SEM (Leica Stereoscan S-260, Cambridge, $\mathrm{UK})$ at 5000x magnifications. 


\section{Mechanical properties}

Five specimens of each material were prepared in moulds of $25 \mathrm{~mm} \times 2 \mathrm{~mm} \times 2 \mathrm{~mm}$ as specified in the ISO specification 4049 [10]. Samples were light-cured using two conventional curing devices (XL 3000, 3M-ESPE, St. Paul, MN, USA, 650mW/cm2) by overlapping irradiations for a total of $60 \mathrm{~s}$ on both sides. The same specimen was used to measure the following properties: dynamic and static moduli of elasticity and Vickers microhardness. Specimens were stored for 7 days in water at $37{ }^{\circ} \mathrm{C}$ before measurement.

\section{Dynamic modulus}

The dynamic modulus of elasticity was measured non-destructively by the impulse excitation technique [2]. Each sample was set in flexural vibration by a light mechanical impulse. The signal produced was captured via a microphone placed underneath the sample by a special signal analyzer, the Grindosonic (Lemmens Elektronics, Haasrode, Belgium). Modulus of elasticity (GPa) was calculated from the fundamental frequency $(\mathrm{Hz})$, the mass $(\mathrm{g})$, the width $(\mathrm{mm})$, the length $(\mathrm{mm})$, and the thickness of the bar $(\mathrm{mm})$, as follows: [11]

$$
E d=0.946 \frac{m f^{2}}{b} \frac{L^{3}}{t^{3}} T_{1}
$$

where $m$ is the mass of the bar, $\mathrm{b}$ is the width of the bar, $L$ is the length of the bar, $t$ is the thickness of the bar, $f t$ is the fundamental frequency of the bar in flexion, which appears on the screen of the machine, and T1 is a correction factor for fundamental flexural mode to account for finite thickness of the bar, Poisson's ratio and other constants. Poisson's ratio is the ratio of transverse strain (contraction) to axial strain (elongation) in a uniaxial tensile test [12]. When applied to dental resin composites, its value lies around 0.30 , which has been taken as the mean value for all the materials tested in this study.

\section{Static modulus}

The static modulus was measured using a three-point bending setup according to the ISO-4049 specification [10]. Samples were loaded in an Instron machine (Instron 5566, High Wycombe, UK) at a speed rate of $0.75 \mathrm{~mm} / \mathrm{min}$ until fracture occurred.

The load and the corresponding deflection were recorded and used to calculate the modulus (GPa) and the strength (MPa):

$\mathrm{Es}=\mathrm{Fl}^{3} / 4 \mathrm{bh}^{3} \mathrm{~d}[11]$.

where $F$ is the load, $l$ is the distance between the supports $(\mathrm{mm}), b$ is the width of the bar $(\mathrm{mm}), h$ is the thickness of the bar (mm), and $\mathrm{d}$ is the deflection corresponding to the load $F$.

\section{Vickers microhardness}

Microhardness measurements were carried out on the fractured samples issued from the previous test with a Durimet microhardness tester (Leitz,Wetzlar, Germany). A load of $200 \mathrm{~g}$ was applied during $30 \mathrm{~s}$ on their surface. The length of the diagonal of each indentation was measured directly using a graduated eye-lens. The Vickers Hardness Number is obtained using the following equation: $\mathrm{H}=1854.4 \times \mathrm{P} / \mathrm{d}^{2}$ where $H$ is Vickers hardness in $\mathrm{kg} / \mathrm{mm}^{2}, P$ is the load in grams and $d$ is the length of the diagonals in $\mu \mathrm{m}[13]$.

\section{Statistical analysis}

Statistical analysis for all the mechanical properties was made using a one-way ANOVA and post hoc Scheffe's tests at $p<0.05$ level. This was performed separately for each of the different mechanical properties.

\section{Results}

\section{Percentage and morphology of inorganic fraction}

The mean values and standard deviations of the size and percentage of fillers by weight are shown in Table 2 and Figure 1 . They ranged from $43.0 \%$ for Monocem to 71.5\% for Panavia F2.0. For the micro-hybrid resin composite Clearfil AP-X used as control, the weight percentage of fillers was $83.5 \%$.

The SEM microphotographs are shown in Figure 2. Irregular shaped particles were found in Maxcem, Monocem and Variolink II. Rely X Unicem showed large irregular shaped filler aggregates. Irregular and spheroidal particles associated with aggregates were found in Panavia F2, Clearfil Esthetic Cement, G-Cem and Clearfil AP-X.

\section{Mechanical properties}

Mean values and standard deviations of the dynamic and static moduli of elasticity of the materials tested are shown in Table 3. Values of the dynamic moduli of elasticity for the luting materials varied between 6.62 GPa for Monocem to 9.79 GPa for G-Cem. The highest value $(11.22 \mathrm{GPa})$ was obtained with the restorative resin composite (Clearfil AP-X). 


\begin{tabular}{|c|c|c|c|}
\hline Cements & $\begin{array}{c}\text { Fillers } \\
\text { percentage (SD) }\end{array}$ & $\begin{array}{c}\text { Fillers } \\
\text { percentage/weight }\end{array}$ & $\begin{array}{c}\text { Fillers } \\
\text { size }\end{array}$ \\
\hline RelyX Unicem & $68.3(0.4)$ & $72 \%$ & $<9.5 \mu \mathrm{m}$ \\
\hline Maxcem & $68.8(1.9)$ & $67 \%$ & $3.6 \mu \mathrm{m}$ \\
\hline Monocem & $43.0(2.8)$ & $60 \%$ & - \\
\hline G-Cem & $66.9(0.9)$ & $71.4 \%$ & $4 \mu \mathrm{m}$ \\
\hline Panavia F2.0 & $71.5(1.8)$ & $70.8 \%$ & $2 \mu \mathrm{m}$ \\
\hline $\begin{array}{c}\text { Clearfil } \\
\text { Esthetic } \\
\text { Cement }\end{array}$ & $69.9(0.4)$ & $70 \%$ & $2.5 \mu \mathrm{m}$ \\
\hline Variolink II & $69.6(3.0)$ & $73 \%$ & $0.04-3.0 \mu$ \\
\hline
\end{tabular}

Mean $=0.7 \mu \mathrm{m}$

Table 2: Fillers sizes and percentage of the composite cements tested (data obtained after thermogravimetric analysis (TGA) and technical information provided by the respective manufacturers)

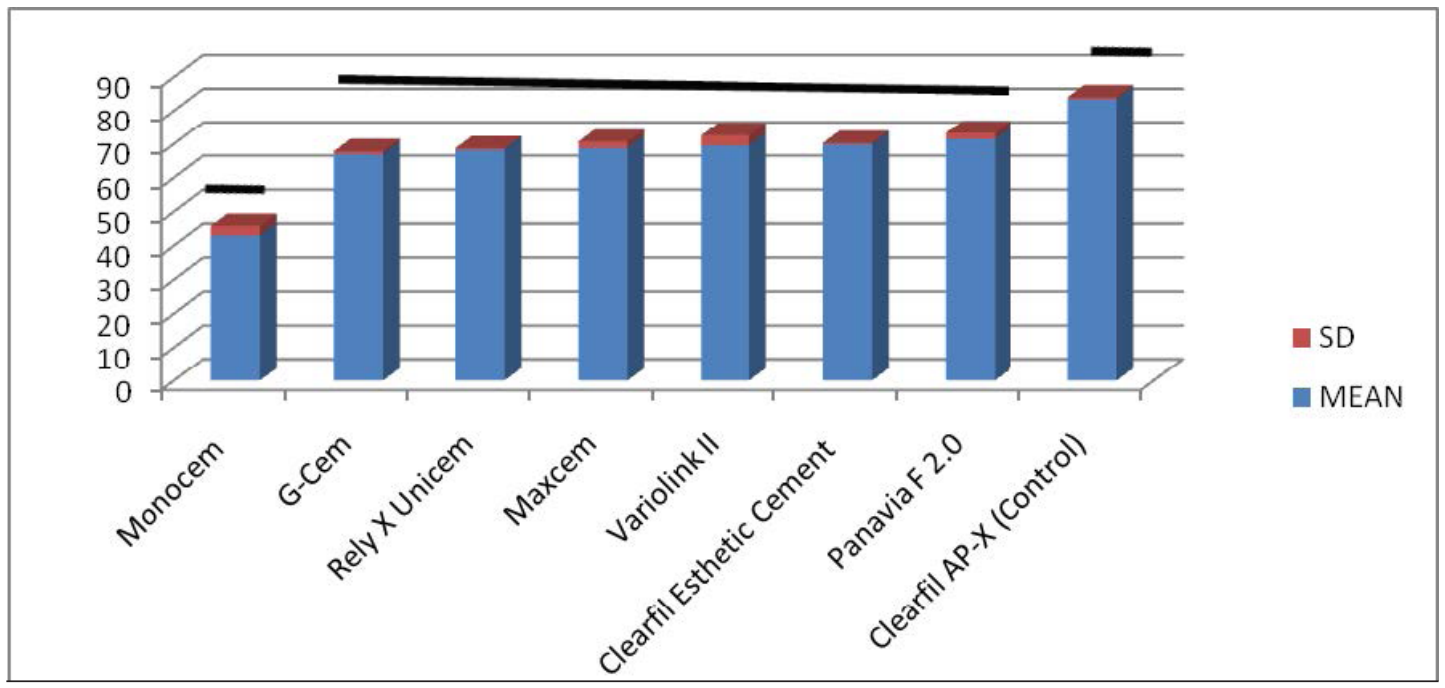

Figure 1: Mean values and SD of the percentage of filler by weight of the composites cements determined by TGA. (Horizontal bars connect values that are not statistically significant $(p<0.05)$ )
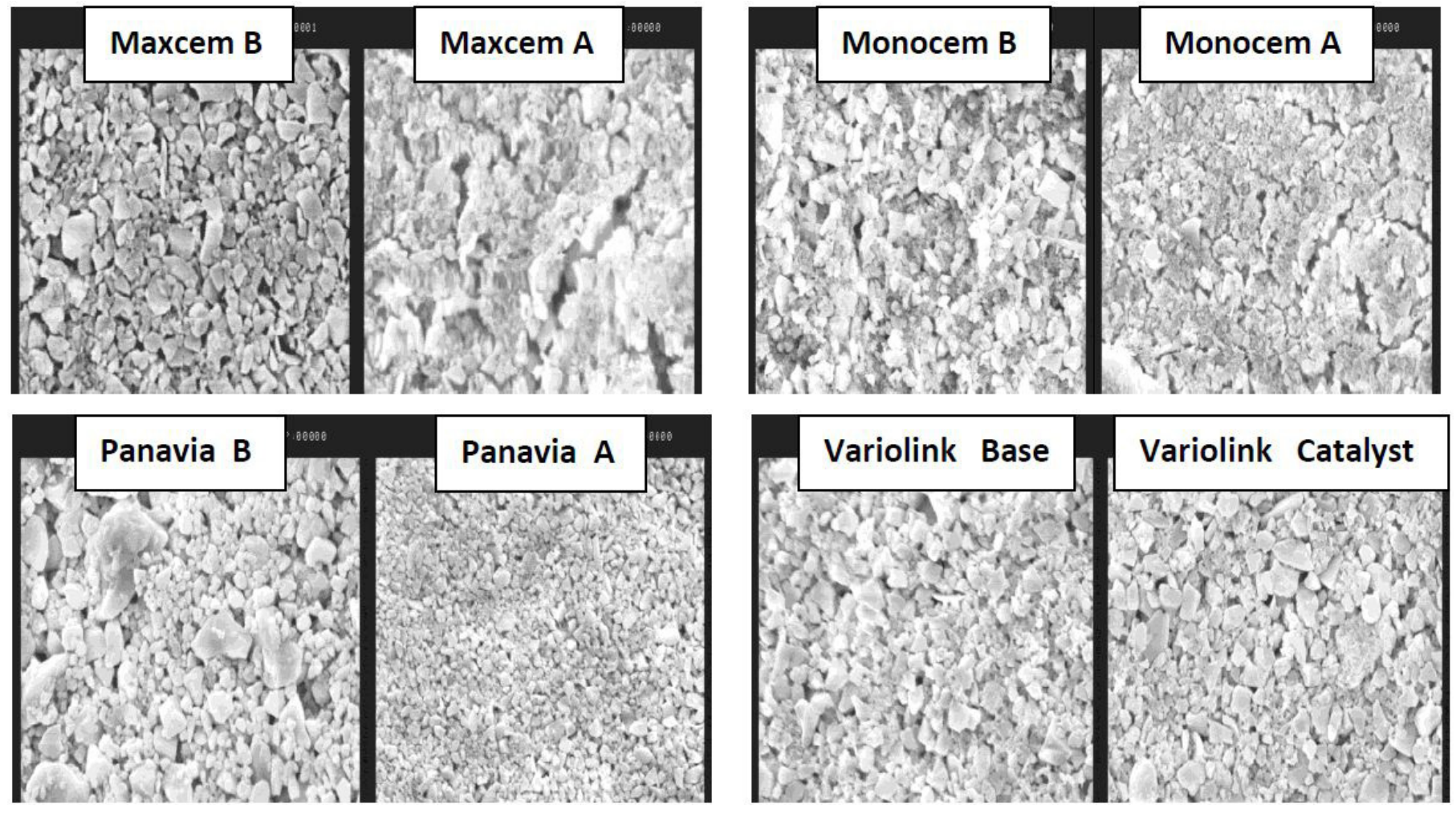

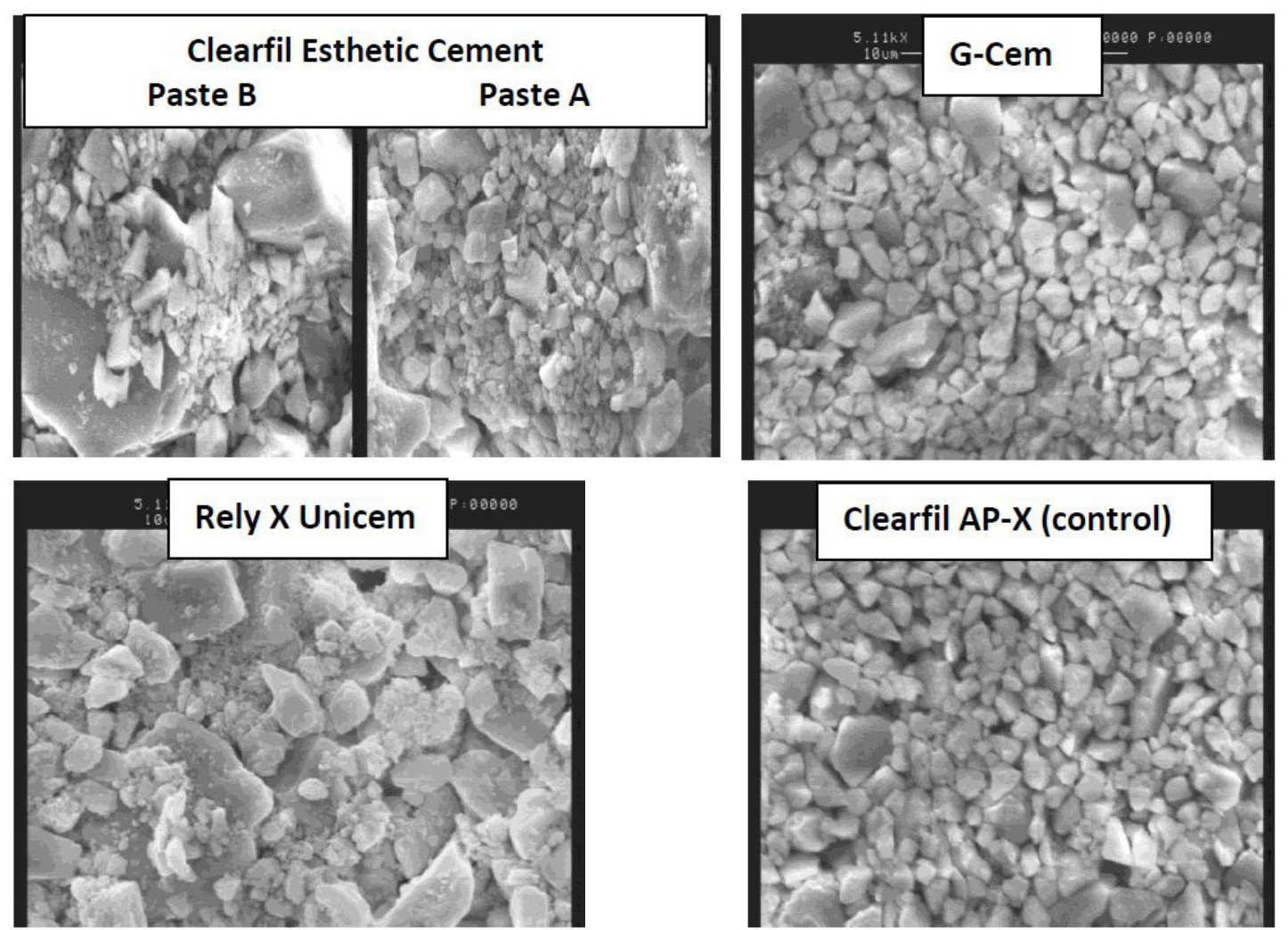

Figure 2: Fillers of studied luting cements by Scanning Electron Microscopy at 5000X magnifications

\begin{tabular}{|c|c|c|c|c|}
\hline \multirow[t]{2}{*}{ Cements } & \multicolumn{2}{|c|}{ Dynamic moduli of elasticity } & \multicolumn{2}{|c|}{ Static moduli of elasticity } \\
\hline & Mean & SD & Mean & SD \\
\hline Monocem & $6.62^{\mathrm{a}}$ & 0.341 & $17.99^{f}$ & 2.32 \\
\hline Maxcem & $8.04^{\mathrm{b}}$ & 0.325 & $24.36^{\mathrm{g}}$ & 5.84 \\
\hline Variolink II & $8.17^{\mathrm{b}}$ & 0.149 & $26.66^{\mathrm{g}}$ & 6.66 \\
\hline Panavia F2.0 & $8.32^{\mathrm{b}}$ & 0.448 & $25.18^{\mathrm{g}}$ & 5.03 \\
\hline Unicem & $8.94^{\mathrm{b}}$ & 0.112 & $13.47^{\mathrm{e}}$ & 2.3 \\
\hline $\begin{array}{c}\text { Clearfil Esthetic } \\
\text { Cement }\end{array}$ & $9.53^{\mathrm{b}}$ & 0.444 & $35.09^{\mathrm{h}}$ & 5.52 \\
\hline G-Cem & $9.79^{\mathrm{b}}$ & 1.016 & $9.70^{\mathrm{d}}$ & 0.95 \\
\hline Clearfil AP-X & $11.22^{\mathrm{c}}$ & 0.192 & $50.49^{\mathrm{i}}$ & 6.67 \\
\hline
\end{tabular}

Table 3: Dynamic and static moduli of elasticity of the materials tested

Values for the static moduli of elasticity ranged from 9.70 GPa for G Cem to 35.09 GPa for Clearfil Esthetic Cement. Clearfil AP-X with a value of $50.49 \mathrm{GPa}$ have the highest static moduli of elasticity.

The results for Vickers microhardness ranged from 17.20 for Monocem to 54.58 for Clearfil Esthetic Cement. Mean values and standard deviations are shown in Table 4.

\begin{tabular}{|c|c|c|}
\hline Cements & Mean & SD \\
\hline Monocem & $17.20^{\mathrm{a}}$ & 0.28 \\
\hline Maxcem & $27.12^{\mathrm{b}}$ & 2.42 \\
\hline Panavia F 2.0 & $27.56^{\mathrm{b}}$ & 3.25 \\
\hline GCem & $35.68^{\mathrm{c}}$ & 7.08 \\
\hline Variolink II & $45.52^{\mathrm{d}}$ & 2.05 \\
\hline Unicem & $50.44^{\mathrm{e}}$ & 4.05 \\
\hline $\begin{array}{c}\text { Clearfil Esthetic } \\
\text { Cement }\end{array}$ & $54.58^{\mathrm{e}}$ & 5.07 \\
\hline Clearfil AP-X & $105.00^{\mathrm{b}}$ & 1.41 \\
\hline
\end{tabular}




\section{Discussion}

\section{Filler load}

The use of thermogravimetric analysis (TGA) is a good method to determine the filler load in weight of dental resin composites, as demonstrated by several authors $[12,13]$. This method consists on heating the specimens gradually under air flow with a cycle of $20 \pm 5{ }^{\circ} \mathrm{C} \cdot \mathrm{min}^{-1}$ to $725^{\circ} \mathrm{C}$ or $800{ }^{\circ} \mathrm{C}[14,15]$. This procedure allows a precise follow-up of the disintegration of each organic component [11].

The TGA technique was used in our study in order to determine the inorganic fraction of tested cements. Different others authors used the ashing in air technique which is based on the elimination of the organic fraction of the composite by heating at a constant temperature [4,16-18]. The stable patterns observed with TGA curves after $750{ }^{\circ} \mathrm{C}$ allowed us to validate this technique which can be a good alternative to ashing in air technique.

The percentages of fillers vary widely among the cements. In some cases, differences were found between our TGA's data and those given by the manufacturers. One possible explanation is variable layer thickness and amount of silane. Indeed, manufacturers functionalize the particles' surface according to their own proprietary methods and use different methods to measure the percentage of fillers. Some manufacturers seem to assess the percentage of fillers by weight before the silanization process of the fillers while others include the percentage of silane coating in their calculations [16].

Our results showed that our TGA percentages are generally close to those given by manufacturers while differences were noticed for some of the resin cements. This was the case for GCem (-5\%) and Monocem (-17\%).

\section{Filler shape}

Most filler particles are of irregular shape. Irregular shaped particles were found in Maxcem, Monocem and Variolink II. Bayne, et al. showed that spherical shape is known to allow an increased filler load in resin composites [19]. According to Suzuki, et al. spherical shaped particles contribute to enhance fracture strength of these materials as compared with irregularly shaped ones since mechanical stresses tend to concentrate on the angles and protuberances of the particles [20]. Rely X Unicem contains large filler aggregates while Panavia F2, Clearfil Esthetic Cement, G-Cem and Clearfil AP-X present combinations of irregular and spheroidal particles associated with aggregates. Clinically, the liquid and powder forms prepared by manually mixing the cements were found to cause greater porosity [21]. This situation can be observed for Panavia F2, Clearfil Esthetic Cement and variolink II which are prepared by mixing equal amount of paste $\mathrm{A}$ and $\mathrm{B}$ while the others are presented in capsule.

\section{Mechanical properties}

An ideal dental material should mimic structural, mechanical and physical characteristics of dentin and enamel [6]. Luting cements, as an interface between a tooth and another restorative material, should of course behave as close as possible like tooth tissues. Xu, et al. measured the elastic modulus of human enamel and dentin and obtained a mean value of $19 \mathrm{GPa}$ for the dentin [22]. Young's modulus of enamel was $94 \mathrm{GPa}$ while depending significantly on tooth orientation. The mechanical properties of all the cements tested in this study are far from those of enamel and dentin.

Since the cement properties are very close to those of composite, we can hypothesize that, like resin composite, cement with high mechanical properties (i.e. modulus of elasticity, flexural strength, tensile strength and fracture toughness) would better resist to occlusal loads than cement with low mechanical properties.

In our study, Clearfil AP-X shows the higher Vickers microhardness followed by Clearfil Esthetic Cement and Unicem. These findings are in accordance with Sabbagh, et al. who showed that hardness may be influenced by degree of set of the organic phase as well as by its filler content [2]. The author found high correlation between the percentage of fillers by weight and the hardness, which explains the low values obtained with lower filled composites. In our study, the same correlation is found with the lower filled cement Monocem (60\% of filler by weight, $43 \%$ by TGA) which showed lower Vickers Microhardness. In addition, Clearfil Esthetic Cement revealed few and short resin tags formation at TEM and SEM bonding interface analyses [23].

Regarding the dynamic elastic moduli, values ranged from $6.62 \mathrm{GPa}$ to $11.22 \mathrm{GPa}$. The Clearfil AP-X (control) showed the highest value. No statistically significant differences were found between materials except for Monocem.

For static elastic moduli, considerable differences were found between the materials. The values ranged between 9.70 for G-Cem and 50.49 for Clearfil AP-X. Wide variations in elastic moduli were found for some cements. This is the case for GCem which showed among the best dynamic moduli and worst static moduli. The clinical behavior of this cement may be affected by this fact and this should be taken into account during their use. Peumans, et al. reported that the percentage of adhesive failures is higher for CAD/CAM materials with higher flexural strength [24].

The composition and the storage media affected significantly the sorption and solubility behavior of the cements. Thus, as hydrophobic resin cement with higher filler content showed the least sorption and solubility these types of resin-based luting cements are recommended to be used clinically [25]. 
The null hypothesis stating that there is no difference in fillers percentage between manufacturers and TGA's data among cements must be accepted excepted for G-Cem and Monocem Limitation of this study is the lack of informations regarding manufacturers procedures of silanization.

\section{Conclusion}

Within the limitations of this study, the following conclusions could be retained:

a. The percentages of fillers vary widely among the cement and for some cements, differences were found between our TGA's data and those given by the manufacturers.

b. Filler shapes are irregular or spheroidal associated with aggregates.

c. Variations in filler percentage and morphology were found among some of the tested materials and will probably affect the mechanical properties of luting materials.

d. Studies should be conducted between shape and percentage of fillers by weight and the mechanical properties of resin cements.

\section{Acknowledgements}

The authors would like to thank the manufacturers for supplying materials.

\section{References}

1. Moszner N and Salz U (2001) New developments of polymeric dental composites. Progr Polym Sci 26: 535-76.

2. Sabbagh J (2004) Physical and mechanical characterization of resin-based materials. PhD Thesis, Belgium.

3. Braem, Finger W, Van Doren VE, Lambrechts P, Vanherle G (1989) Mechanical properties and filler fraction of dental composites. Dent Mater 5: 346-9.

4. Chung KH, Greener EH (1990) Correlation between degree of conversion, filler concentration, and mechanical properties of posterior composite resins. J Oral Rehabil 17: 487-94.

5. Abe Y, Vreven J, Leloup G (2001) Dynamic elastic modulus of “packable” composites. Dent Mater; 17: 520-5.

6. Sabbagh J, Vreven J, Leloup G (2002) Dynamic and static modulus of elasticity of resin based materials. Dent Mater 18: 64-71.

7. Miyasaka T (1996) Effect of shape and size of silanated fillers on mechanical properties of experimental photocure composite resins. Dent Mat J 15: 98-110.

8. Kim KH, Ong JL, Okuno O (2002) The effect of filler loading and morphology on the mechanical properties of contemporary composites. J Prosthet Dent 87: $642-9$.

9. Lang BR, Jaarda M. Wang RF (1992) Filler particle size and composite resin classification systems. J Oral Rehabil 19: 569-84.

10. International Organization for Standardization (1988) Specification of dentistry - resin-based filling materials. ISO-4049.

11. Sabbagh J, Ryelandt L, Bachérius L, Biebuyck JJ, Vreven J, et al. (2004) Characterization of the inorganic fraction of resin composites. J Oral Rehabil 31: 1090-101.

12. Chung SM, Yap AU, Koh WK, Tsai KT, Lim CT (2004) Measurement of Poisson's ratio of dental composite restorative materials. Biomaterials 25: 2455-60.

13. Chabrier F, Lloyd CH, Scrimgeour SN (1999) Measurement at low strain rates of the elastic properties of dental polymeric materials. Dent Mater 15: 33-8.

14. Beun S, Glorieux T, Devaux J, Vreven J, Leloup G (2007) Characterization of nanofilled compared to universal and microfilled composites. Dent Mater 23: 51-9.

15. Tyas MJ, Jones DW, Rizkalla AS (1998) The evaluation of resin composite consistency. Dent Mater 14: 424-8.

16. Khan AM et al. (1992) Characterization of inorganic fillers in visible light-cured dental composite resins. J Oral Rehabil 19: 361-70.

17. Oysaed H and Ruyter E (1986) Water sorption and filler characteristics of composites for use in posterior teeth. J Dent Res 65: $1315-18$.

18. Hosoda H, Yamada T, Inokoshi S (1990) SEM and elemental analysis of composites resins. J Prosthet Dent 64: 669-76.

19. Bayne S, Thompson JY, Swift EJ Jr, Stamatiades P, Wilkerson M (1998) A characterization of first generation flowable composites. J Am Dent Assoc 129: 567-77. 20.Suzuki S, Leinfelder KF, Kawai K, Tsuchitani Y (1995) Effect of particle variation on wear rates of posterior composites. Am J Dent 8: 173-8.

21. Malkoç MA, Sevimay M, Tatar İ, Çelik HH (2015) Micro-CT Detection and Characterization of Porosity in Luting Cements. J Prosthodont 5. doi: 10.1111/ jopr.12251.

22. Xu HHK, Smith DT, Jahamir S, Romberg E, Kelly JR, Thompson VP (1998) Indentation damage and mechanical properties of human enamel and dentin. J Dent Res 77: 472-80.

23. Aguiar TR, Vermelho PM, André CB, Giannini M (2013) Interfacial ultramorphology evaluation of resin luting cements to dentin: a correlative scanning electron microscopy and transmission electron microscopy analysis. Microsc Res Tech 76: 1234-9.

24. Peumans M, Valjakova EB, De Munck J, Mishevska CB, Van Meerbeek B (2016) Bonding effectiveness of luting composites to different CAD/CAM materials. J Adhes Dent 18: 289-302.

25. Giti R, Vojdani M, Abduo J, Bagheri R (2016) The comparison of sorption and solubility behavior of four different resin luting cements in different storage media. J Dent Jun 17: 91-7. 


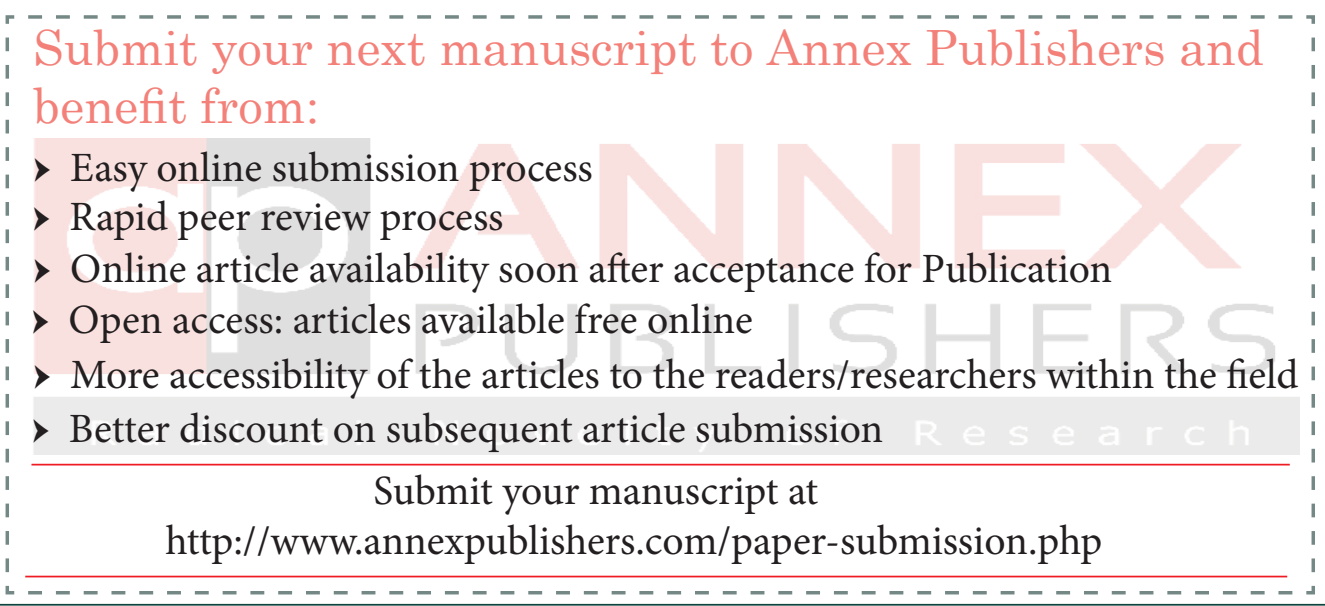

